\title{
Características da carcaça de cordeiros alimentados com dietas contendo diferentes níveis de fibra em detergente neutro ${ }^{1}$
}

\section{Cleber Cassol Pires², Diego Barcelos Galvani ${ }^{3}$, Sérgio Carvalho4, Adriano Ramos Cardoso 5 , Bernardo Garziera Gasperin 5}

\author{
1 Parte da dissertação de Mestrado apresentada pelo quarto autor à UFSM. \\ 2 Depto Zootecnia, UFSM, Campus Camobi, CEP: 97105-900, Santa Maria - RS. Pesquisador do CNPq. \\ 3 Programa de Pós-graduação em Zootecnia, UFSM, Bolsista Capes. \\ ${ }^{4}$ Centro Universitário Feevale. \\ 5 Curso de Medicina Veterinária, UFSM.
}

RESUMO - Este estudo foi conduzido com o objetivo de avaliar o efeito de diferentes níveis de FDN na dieta sobre as características de carcaça de cordeiros confinados e abatidos com $30 \mathrm{~kg}$ de PV. Foram utilizados 20 cordeiros machos, nãocastrados, cruza Ile de France x Texel, distribuídos aleatoriamente em quatro tratamentos (25, 31, 37 e 43\% de FDN na dieta) O volumoso utilizado foi silagem de sorgo híbrido (AG 2005 E) e o concentrado foi composto de milho desintegrado, farelo de soja, sal comum, calcário calcítico e fosfato bicálcico. As dietas foram isoprotéicas (17\% de PB) e as características avaliadas foram: peso de carcaça quente (PCQ), peso de carcaça fria (PCF), rendimento de carcaça quente (RCQ), rendimento de carcaça fria (RCF), índice de quebra ao resfriamento (IQ), área de olho-de-lombo (AOL), espessura de gordura subcutânea (EG), comprimento da carcaça (CC), largura da perna (LP), profundidade do peito (PPEITO), comprimento de perna (CPERNA), peso e proporção de perna, paleta, costilhar e pescoço e pesos e proporções de osso, músculo e gordura da perna dos cordeiros. O aumento do nível de FDN nas dietas reduziu linearmente o PCQ, PCF, RCQ, RCF e o peso de costilhar. Houve efeito quadrático do nível de FDN sobre o CPERNA. As demais variáveis analisadas não foram influenciadas pelos níveis de FDN das dietas.

Palavras-chave: confinamento, cortes, fibra, ovinos

\section{Carcass characteristics of lambs fed diets with different neutral detergent fiber levels}

\begin{abstract}
The objective of this trial was to evaluate the effect of different dietary NDF levels on carcass characteristics of feedlot lambs slaughtered with $30 \mathrm{~kg}$ of body weight. Twenty crossbred Ile de France $\mathrm{x}$ Texel noncastrated male lambs were randomly assigned to the following treatments: $25 \%, 31 \%$, 37\%, and $43 \%$ of dietary NDF. The forage portion of the diet was composed by sorghum silage (hybrid AG 2005 E) and the concentrate by cracked corn, soybean meal, salt, limestone, and dicalcium phosphate. Diets were isonitrogenous averaging $17 \%$ of crude protein. The following variables were measured: hot carcass weight $(\mathrm{HCW})$, cold carcass weight $(\mathrm{CCW})$, hot carcass yield (HCY), cold carcass yield (CCY), cooling loss index (CLI), loin eye area (LEA), subcutaneous fat thickness (SFT), carcass length (CL), hind leg width (LW), chest depth (CP), hind leg length (LL), and weight and proportion of hind leg, shoulder clod, rib, and neck. Weight and proportion of hind leg bone, muscle, and fat also were measured in this trial. Increasing NDF from 25 to $43 \%$ in the diet linearly reduced HCW, CCW, HCY, CCY, and rib weight. A significant quadratic effect of dietary NDF level on LL was also found. No significant effects of the different dietary NDF levels were observed for the remaining variables.
\end{abstract}

Key Words: cuts, feedlot, fiber, sheep

\section{Introdução}

A ovinocultura tem se mostrado com grande potencial para aumento da oferta de proteína animal de alta qualidade, porém, em muitas regiões do país, a atividade é ainda de pouca expressão, em decorrência da estrutura de comercialização precária e da baixa qualidade das carnes normalmente oferecidas aos consumidores (Osório et al., 1998a). Para que a atividade se torne regionalmente importante, é necessário, além de melhorar a comercialização, aumentar os índices produtivos e a qualidade do produto oferecido (Cardoso et al., 2004).

Os cordeiros constituem potencialmente a categoria ovina que possui a carne de maior aceitabilidade pelo mercado consumidor, haja vista suas melhores características de carcaça e a melhor qualidade de sua carne. No 
entanto, o sistema de criação adotado no Sul do Brasil, predominantemente extensivo, resulta muitas vezes em baixos índices produtivos e em produtos de qualidade inferior à daqueles nos quais são empregadas tecnologias mais modernas. O confinamento é uma alternativa que possibilita a terminação de cordeiros com maior rapidez, contudo, os elevados custos dos insumos, principalmente concentrados, muitas vezes impossibilitam a implantação deste sistema.

O balanceamento das dietas é uma das tecnologias empregadas para aumentar os índices de produtividade da ovinocultura, pois, além de fornecer nutrientes em quantidades adequadas, possibilita ao produtor programar o tempo de abate dos seus animais e obter qualidade e padronização de carcaça. Segundo Neres et al. (2001), a qualidade da dieta e o genótipo são os principais fatores de influência sobre as características de carcaça dos ovinos.

Universalmente, admite-se que a conformação da carcaça seja um dos fatores que mais incidem sobre o valor final de comercialização da carne. Uma conformação adequada indica desenvolvimento proporcional das distintas regiões anatômicas que integram a carcaça, de modo que as melhores conformações são alcançadas quando as partes de maior valor comercial estão bem pronunciadas. De acordo com Dumont et al. (1970), a estimação da conformação da carcaça pode ser feita de forma subjetiva, pela impressão visual que causam as distintas formas (portanto, sujeita a erros do observador), ou de forma objetiva, mediante determinação de medições de comprimento, largura e perímetro de vários pontos da carcaça.

Conforme Osório (1992), a melhor carcaça é aquela que possui máxima proporção de músculos, mínima de ossos e uma proporção de gordura que varia conforme a preferência do consumidor. Além disso, esta gordura deve ser suficiente para garantir as condições de suculência da carne, bem como sua apresentação e conservação. Segundo Galvão et al. (1991), o estudo das proporções dos diferentes tecidos na carcaça é de grande interesse na comparação entre grupos genéticos, assim como entre diferentes sistemas de alimentação. No entanto, Sousa (1993) considera que a dissecação de toda a carcaça, ou de metade apenas, só se justifica em casos especiais, por ser onerosa, trabalhosa e lenta, sendo mais comum a dissecação apenas dos principais cortes comerciais, ou daqueles representativos da composição da carcaça. A paleta e a perna representam mais de $50 \%$ da carcaça, sendo estes cortes os que melhor predizem o conteúdo total dos tecidos na carcaça (Huidobro, 1992). Segundo Lathan et al. (1964), a composição tecidual da perna pode ser um bom indicador da composição tecidual da carcaça.
Geralmente, a comercialização de cordeiros é feita com base em observações no animal vivo, motivo pelo qual o peso vivo é importante. Entretanto, para produtores e consumidores, é importante o conhecimento da contribuição percentual e da quantidade de carne dos diferentes cortes da carcaça. Segundo Huidobro \& Cañeque (1993), a proporção de cada componente é importante na avaliação comercial da carcaça. De acordo com Colomer-Rocher (1986), o rendimento de carcaça é determinado por vários outros componentes corporais e seu valor depende, entre outros fatores, dos pesos relativos de seus cortes, sendo que, para melhorar esse valor, é necessário conhecer aspectos relativos à nutrição, à sanidade, ao manejo, às raças e aos cruzamentos e seus efeitos sobre a composição da carcaça.

O objetivo neste estudo foi avaliar o efeito do fornecimento de níveis crescentes de fibra em detergente neutro na dieta sobre as características da carcaça de cordeiros terminados em confinamento.

\section{Material e Métodos}

O experimento foi conduzido no Setor de Ovinocultura do Departamento de Zootecnia da Universidade Federal de Santa Maria (UFSM), localizada na Depressão Central do Estado do Rio Grande do Sul, no período de agosto a dezembro de 2003. Conforme a classificação de Köppen, o clima da região é o Cfa (subtropical úmido), com precipitação média anual de $1.769 \mathrm{~mm}$, temperatura média anual de $19,2^{\circ} \mathrm{C}$, média mínima de $9,3^{\circ} \mathrm{C}$ em julho e média máxima de $24,7^{\circ} \mathrm{C}$ em janeiro, insolação de 2.212 horas anuais com umidade relativa do ar de $82 \%$ (Moreno, 1961).

Foram utilizados 20 cordeiros machos não-castrados, cruzas Ile de France x Texel, desmamados em média aos 42 dias de idade, distribuídos aleatoriamente em quatro tratamentos $(25,31,37$ e $43 \%$ de FDN). Os animais foram alojados em baias individuais $\left(2 \mathrm{~m}^{2}\right)$ providas de comedouros e bebedouros. Na ocasião, foi realizada vermifugação para o controle de endoparasitas, repetida sempre que necessário, após coleta de fezes diretamente na ampola retal dos cordeiros, para contagem do número de ovos por grama de fezes (OPG), segundo metodologia de Matos \& Matos (1988).

Antes do início do período experimental, os animais passaram por um período de adaptação (7 dias), em que receberam, ad libitum, uma dieta contendo $35 \%$ de FDN e $17 \%$ de PB. Após esse período, foi fornecida a dieta correspondente a cada tratamento. A alimentação foi fornecida duas vezes ao dia, em horários pré-estabelecidos ( 8 e $16 \mathrm{~h}$ ) e em quantidade ajustada para manter $10 \%$ de sobras. $\mathrm{O}$ alimento utilizado foi composto de silagem de sorgo (Sorghum bicolor(L.) Moench), grão de milho quebrado 
(Zea mays L.), farelo de soja (Glycine Max L.) e mistura mineral. A proporção volumoso:concentrado variou conforme os níveis de FDN desejados. As rações utilizadas foram calculadas para serem isoprotéicas, com $17 \%$ de PB (MS) (Tabela 1).

Durante o experimento, foram coletadas amostras dos alimentos fornecidos e das sobras, as quais foram identificadas e acondicionadas em freezer, para posteriores análises laboratoriais. Todas as amostras foram pré-secas em estufa ventilada a $65^{\circ} \mathrm{C}$ e, posteriormente, trituradas em moinho tipo Willey com peneira de $1 \mathrm{~mm}$. A seguir, foram acondicionadas em frascos identificados para determinação das concentrações de MS, MO, FDN, FDA, PB e EE, segundo Silva (1990). Os CT dos alimentos fornecidos e das sobras foram calculados segundo Sniffen et al. (1992), em que CT $(\%)=100-(\% \mathrm{~PB}+\% \mathrm{EE}+\% \mathrm{CIN})$, e os carboidratos não-estruturais (CNE), pela diferença de CT - FDN. Os valores de EM foram estimados com base nas equações propostas por Weiss et al. (1993) e pelo NRC (NRC, 1989). $\mathrm{Na}$ Tabela 2 é apresentada a composição bromatológica da silagem e dos concentrados utilizados na composição das dietas experimentais.

Os abates foram realizados à medida que os animais atingiram $30 \mathrm{~kg}$ de PV, após jejum de sólidos de aproximadamente 12 horas. As carcaças foram imediatamente pesadas para determinação do peso de carcaça quente (PCQ) e do rendimento de carcaça quente (RCQ) e armazenadas em câmara frigorífica a $2^{\circ} \mathrm{C}$ por 24 horas. Após este período, as carcaças foram novamente pesadas para obtenção do peso de carcaça fria (PCF), do rendimento de carcaça fria (RCF) e do índice de quebra ao resfriamento (IQ).

Tabela 1 - Proporções dos ingredientes (\% MS) utilizados nas dietas experimentais

Table 1 - Ingredient composition of the experimental diets (\%DM)

\begin{tabular}{lcccc}
\hline & \multicolumn{4}{c}{$\begin{array}{c}\text { Tratamento (\% FDN) } \\
\text { Treatment (\% NDF) }\end{array}$} \\
\cline { 2 - 5 } $\begin{array}{l}\text { Item (\%) } \\
\text { Item (\%) }\end{array}$ & 25 & 31 & 37 & 43 \\
\hline $\begin{array}{l}\text { Silagem de sorgo } \\
\text { Sorghum silage } \\
\text { Milho quebrado }\end{array}$ & 25,62 & 42,80 & 59,83 & 74,94 \\
$\begin{array}{l}\text { Cracked corn } \\
\text { Farelo de soja }\end{array}$ & 53,85 & 36,05 & 18,80 & 1,25 \\
$\begin{array}{l}\text { Soybean meal } \\
\text { Calcário calcítico }\end{array}$ & 1,17 & 0,90 & 0,80 & 0,45 \\
$\begin{array}{l}\text { Limestone } \\
\text { Fosfato bicálcico }\end{array}$ & 0,00 & 0,15 & 0,20 & 0,67 \\
$\begin{array}{l}\text { Dicalcium phosphate } \\
\text { Sal comum }\end{array}$ & 0,60 & 0,60 & 0,60 & 0,60 \\
\begin{tabular}{l} 
Salt \\
\hline
\end{tabular} & & & & \\
\end{tabular}

Tabela 2 - Teores médios de nutrientes da silagem e dos concentrados utilizados na composição das dietas experimentais

Table 2 - Chemical composition of the silage and concentrate used in the experimental diets

\begin{tabular}{|c|c|c|c|c|c|}
\hline \multirow[b]{2}{*}{$\begin{array}{l}\text { Item }(\%) \\
\text { Item }(\%)\end{array}$} & \multicolumn{4}{|c|}{$\begin{array}{c}\text { Concentrado } \\
\text { Concentrate }\end{array}$} & \multirow[t]{2}{*}{$\begin{array}{c}\text { Silagem } \\
\text { Silage }\end{array}$} \\
\hline & 25 & 31 & 37 & 43 & \\
\hline $\operatorname{MS}(D M)$ & 89,39 & 89,21 & 89,23 & 89,78 & 35,52 \\
\hline $\mathrm{MO}(O M)$ & 94,94 & 94,33 & 93,36 & 91,01 & 94,94 \\
\hline $\mathrm{PB}(C P)$ & 19,85 & 25,06 & 31,12 & 40,56 & 6,25 \\
\hline $\mathrm{EE}$ & 2,84 & 2,44 & 2,61 & 2,58 & 2,55 \\
\hline $\mathrm{FDN}(N D F)$ & 11,60 & 10,91 & 11,37 & 14,92 & 53,74 \\
\hline FDA $(A D F)$ & 1,52 & 1,39 & 1,56 & 3,92 & 27,95 \\
\hline $\mathrm{CHT}(T C H)$ & 72,08 & 66,73 & 59,42 & 47,75 & 85,82 \\
\hline CNE (NSC) & 60,65 & 55,93 & 48,33 & 32,97 & 32,44 \\
\hline $\mathrm{EM}(M E)(\mathrm{Mcal} / \mathrm{kg})$ & 3,17 & 3,00 & 3,20 & 3,08 & 2,06 \\
\hline $\mathrm{Ca}$ & 0,68 & 0,76 & 0,90 & 1,18 & 0,34 \\
\hline $\mathrm{P}$ & 0,41 & 0,48 & 0,60 & 0,87 & 0,17 \\
\hline
\end{tabular}

A área de olho-de-lombo foi obtida pela exposição do músculo Longissimus dorsi após um corte transversal na carcaça, entre a 12 $\underline{a}$ e $13 \underline{a}$ costelas, traçando seu contorno em papel vegetal (Müller, 1980). Para determinação e registro da área, foi utilizado o programa SITER 3.1 modelo A2 descrito por Giotto (2001). Na mesma região, foi tomada a espessura de gordura de cobertura com o uso de paquímetro.

Na meia-carcaça direita, foi medido o comprimento de carcaça (distância entre o bordo anterior da sínfise ísquiopubiana e o bordo anterior da primeira costela no seu ponto médio), o comprimento de perna (distância entre o bordo anterior da sínfise ísquio-pubiana e a porção média dos ossos do tarso), a profundidade de peito (distância máxima entre o dorso e o esterno) e a largura de perna (distância entre os bordos interno e externo da parte superior da perna em sua parte mais larga). Todas as avaliações foram realizadas segundo metodologias descritas por Osório et al. (1998b).

Posteriormente, na meia-carcaça direita, foi realizada a separação regional em pescoço, paleta, costilhar e perna (quarto). Depois de pesadas as partes, a perna foi dissecada em osso, músculo e gordura, sendo cada componente pesado separadamente.

O delineamento experimental utilizado foi o inteiramente casualizado, com quatro tratamentos e cinco repetições, sendo cada cordeiro considerado uma unidade experimental. Os dados foram submetidos às análises de variância e de regressão, com auxílio do pacote estatístico SAS (SAS, 1997).

O modelo matemático utilizado foi:

$$
\mathrm{Y}_{\mathrm{ij}}=\mu+\tau_{\mathrm{i}}+\varepsilon_{\mathrm{ij}}
$$


em que: $\mathrm{Y}_{\mathrm{ij}}=$ observações das variáveis dependentes correspondentes à repetição da independente $\mathrm{j}$ sob o tratamento de ordem $\mathrm{i} ; \mu=$ média geral das observações; $\tau_{\mathrm{i}}=$ efeito do tratamento de ordem $\mathrm{i} ; \varepsilon_{\mathrm{ij}}=$ erro aleatório residual, associado a observação de ordem j sob o tratamento de ordem i, NID $\left(0, v^{2}\right)$.

Após selecionado o erro pelo modelo, foi ajustado o seguinte modelo de regressão polinomial:

$$
Y_{i j}=\alpha+\beta_{1} x_{i j}+\beta_{2} x^{2}{ }_{i j}+\beta_{3} x^{3}{ }_{i j}+\varphi
$$

em que: $Y_{i j}=$ observações das variáveis dependentes correspondentes à repetição da independente $\mathrm{j}$ sob o tratamento de ordem $\mathrm{i} ; \alpha, \beta_{1}, \beta_{2}$ e $\beta_{3}=$ são os parâmetros da equação; $x_{i j}=$ observação da variável independente associada à repetição de ordem $\mathrm{j}$ sob tratamento de ordem i; $\varphi=$ desvios da regressão.

O modelo adotado, segundo o grau da polinomial foi selecionado de acordo com a significância do teste $\mathrm{F}$ e os coeficientes de regressão, adotando-se o nível de 5\% de probabilidade.

\section{Resultados e Discussão}

Na Tabela 3 são apresentadas as médias dos valores referentes ao peso inicial, peso ao abate, dias para atingir o peso ao abate e ganho de peso médio diário, de acordo com o nível de FDN das dietas.

$\mathrm{O}$ aumento do teor de fibra na dieta dos cordeiros promoveu redução linear $(\mathrm{P}<0,01)$ no ganho de peso médio diário, elevando, conseqüentemente, o número de dias necessários para atingir o peso de abate estabelecido. Para cada unidade percentual de adição de fibra na dieta, houve aumento de 1,75 dias para atingir o peso de abate.

Como demonstrado na Tabela 4, houve efeito significativo $(\mathrm{P}<0,05)$ dos níveis de FDN sobre os pesos de carcaça quente e fria e os rendimentos de carcaça quente e fria, demonstrando que a elevação dos níveis de fibra na dieta reduz o peso e o rendimento da carcaça. De acordo com Sainz (1996), o peso de carcaça é influenciado pela velocidade de crescimento, pela idade ao abate e pelo regime nutricional dos animais. O rendimento de carcaça é altamente influenciado pelo peso vivo do animal, que, por sua vez, sofre efeitos do peso do conteúdo gastrintestinal (Lawrence \& Fowler, 1997; Patterson et al., 1995; Owens \& Gill, 1995). Dessa forma, os resultados encontrados podem ser explicados pelo efeito redutor do aumento do teor de fibra na dieta sobre a velocidade de passagem do alimento pelo trato gastrintestinal, o que fez com que os animais alimentados com maior teor de FDN tivessem maior quantidade de alimento no trato digestivo no momento de abate. Siqueira
Tabela 3 - Valores médios para peso inicial (PI), peso ao abate (PA), dias para atingir o peso ao abate (dias) e ganho de peso médio diário (GMD) de cordeiros alimentados com dietas contendo diferentes níveis de FDN

Table 3 - Average values for initial body weight (IBW), slaughter weight $(S L)$, days to reach the slaughter age days), and daily average weight gain (DWG) on lambs fed diets with different NDF levels

\begin{tabular}{|c|c|c|c|c|c|c|c|}
\hline \multirow[b]{2}{*}{ Item } & \multicolumn{4}{|c|}{$\begin{array}{c}\text { Nível de FDN } \\
\text { NDF level }\end{array}$} & \multirow[t]{2}{*}{$\mathrm{CV}(\%)$} & \multirow[t]{2}{*}{$\mathrm{R}^{2}$} & \multirow[t]{2}{*}{$\begin{array}{l}\text { Equação } \\
\text { Equation }\end{array}$} \\
\hline & 25 & 31 & 37 & 43 & & & \\
\hline PI & 20,26 & 20,09 & 18,66 & 18,31 & - & 14,94 & $\hat{\mathrm{Y}}=19,28$ \\
\hline $\begin{array}{l}I B W \\
\text { PA } \\
S W\end{array}$ & 30,84 & 31,52 & 30,11 & 30,92 & - & 3,31 & $\hat{\mathrm{Y}}=30,80$ \\
\hline $\begin{array}{l}\text { Dias } \\
\text { Days }\end{array}$ & 33,20 & 38,25 & 47,60 & 70,50 & 0,40 & 36,49 & 1 \\
\hline $\begin{array}{l}\text { GMD } \\
D W G\end{array}$ & 0,321 & 0,318 & 0,239 & 0,188 & 0,60 & 17,23 & 2 \\
\hline
\end{tabular}

1 - Idade $=-11,04+1,75 \mathrm{FDN}^{* *}$

$2-$ GMD $=0,498-0,007 F^{*} N^{* *}$.

** Significativo a $1 \%$ de probabilidade pelo teste F.

** Significant at $1 \%$ probability by $F$ test.

\& Fernandes (1999) concluíram que o conteúdo gastrintestinal pode promover, com as variações dos seus pesos, importantes oscilações no rendimento de carcaça. Os resultados obtidos neste trabalho foram semelhantes aos encontrados por Motta et al. (2001), que observaram melhores pesos e rendimentos de carcaça em cordeiros alimentados com maior quantidade de concentrado.

Segundo Martins et al. (2002), o índice de quebra ao resfriamento (IQ) indica o percentual de peso perdido durante o resfriamento da carcaça, em decorrência de fatores como perda de umidade e reações químicas que ocorrem no músculo. Assim, quanto menor esse percentual, maior a probabilidade de a carcaça ter sido manejada e armazenada de modo adequado. Neste experimento, o percentual de IQ não sofreu influência significativa $(P>0,05)$ dos níveis de FDN nas dietas. Perdas decorrentes do resfriamento semelhantes às deste trabalho foram verificadas por Almeida Jr. et al. (2004), que, avaliando níveis de substituição $(0,50$ e $100 \%$ ) de grãos secos de milho pela silagem de grãos úmidos de milho na dieta de cordeiros criados e terminados em creep feeding, observaram valor médio de $2,9 \%$.

A área de olho-de-lombo (AOL) e a espessura de gordura subcutânea (EG) não foram influenciadas $(\mathrm{P}>0,05)$ pelos níveis de fibra das dietas. Garcia et al. (2003), testando diferentes níveis de energia na dieta de cordeiros Suffolk alimentados em creep feeding, também não encontraram diferenças na AOL entre os tratamentos ao abaterem os animais com $31,0 \mathrm{~kg}$ de $\mathrm{PV}$. O valor médio observado por esse autor para AOL foi de $12,62 \mathrm{~cm}^{2}$, pouco superior ao encontrado neste experimento. Áreas menores foram obtidas 
Tabela 4 - Valores médios para peso de carcaça quente (PCQ), peso de carcaça fria (PCF), rendimento de carcaça quente (RCQ), rendimento de carcaça fria (PCF), índice de quebra ao resfriamento (IQ), área de olho-de-lombo (AOL) e espessura de gordura subcutânea (EG) de cordeiros alimentados com dietas com diferentes níveis de FDN

Table 4 - Average values for hot carcass weight (HCW), cold carcass weight (CCW), hot carcass yield ( $\mathrm{HCY}$ ), cold carcass yield (CCY), cooling loss index (CLI), loin eye area (LEA), subcutaneous fat thickness (SFT) on lambs fed diets with different NDF levels

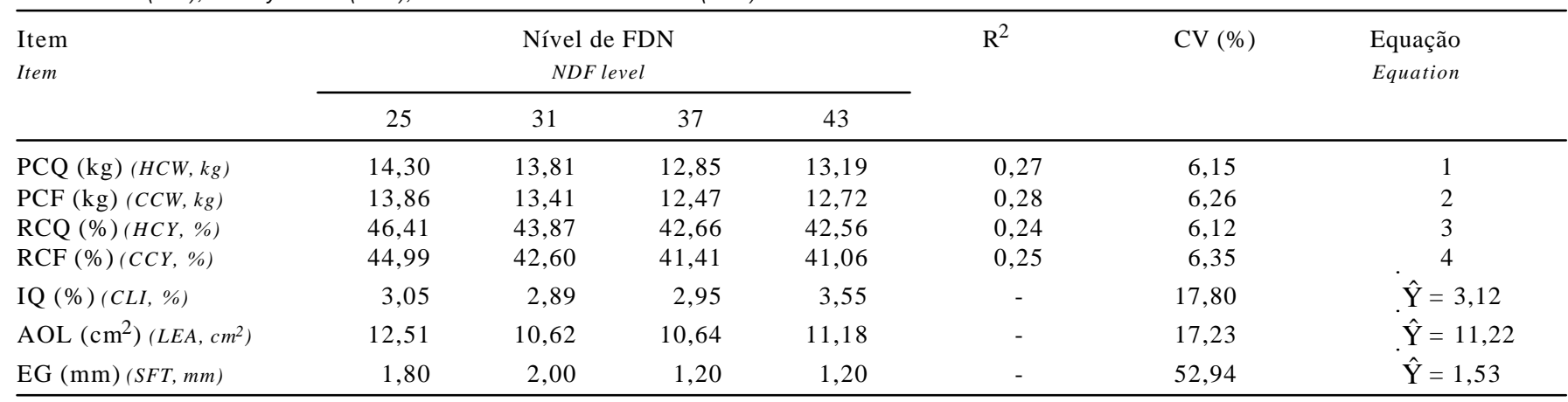

$1-\mathrm{PCQ}=15,539-0,060 F \mathrm{FN}^{*}$

$2-\mathrm{PCF}=15,157-0,062 \mathrm{FDN}^{*}$

$3-\mathrm{RCQ}=49,919-0,181 \mathrm{FDN}^{*}$

$4-\mathrm{RCF}=48,700-0,186 \mathrm{FDN}{ }^{*}$

* Significativo a $5 \%$ de probabilidade pelo teste $F$.

* Significant at $5 \%$ probability by $F$ test.

por Cunha et al. (2000), que verificaram, em cordeiros mestiços Suffolk abatidos aos $33,7 \mathrm{~kg}$ de PV, valor médio de $10,30 \mathrm{~cm}^{2}$, e Silva \& Pires (2000), que registraram valor médio de 10,97 $\mathrm{cm}^{2}$ em cordeiros mestiços Texel x Ideal abatidos com $28 \mathrm{~kg}$ de peso vivo.

Não houve efeito dos níveis de fibra das dietas $(\mathrm{P}>0,05)$ sobre o comprimento da carcaça, a largura da perna e a profundidade de peito (Tabela 5). No entanto, houve efeito quadrático dos níveis de FDN sobre o comprimento de perna.

Os valores médios das medidas de carcaça, de modo geral, foram próximos aos observados por Siqueira \& Fernandes (2000) e Garcia (1998), que realizaram experimentos com cordeiros em sistema de terminação em confinamento. Também corroboram os valores registrados por Macedo et al. (2000), em ovinos em crescimento terminados em confinamento e/ou pastejo. Entretanto, os resultados das mensurações das carcaças foram inferiores aos observados por Garcia et al. (2000), em cordeiros de diferentes grupos genéticos (Texel x Bergamácia; Texel x Santa Inês e Santa Inês puros) abatidos com 130 dias de idade, porém, com diferentes pesos. Esses autores concluíram que os mestiços apresentaram superioridade em relação aos Santa Inês puros, confirmando que estas medidas são influenciadas, sobretudo, pelo genótipo. Como neste experimento os animais pertenciam ao mesmo grupo genético, justifica-se a ausência de diferenças significativas.

Os dados médios referentes aos pesos e às proporções dos cortes comerciais da carcaça dos cordeiros encontram-se na Tabela 6. A análise de regressão comprovou influência significativa $(\mathrm{P}<0,05)$ do nível de FDN sobre o peso de costilhar, que diminuiu linearmente com o incremento de fibra das dietas. Este comportamento, possivelmente, está
Tabela 5 - Valores médios para comprimento da carcaça (CC), largura da perna (LP) profundidade do peito (PPEITO) e comprimento de perna (CPERNA) de cordeiros alimentados com dietas com diferentes níveis de FDN

Table 5 - $\quad$ Average values for carcass length $(C L)$, leg width $(L W)$, chest depth $(C P)$ and leg length (LL) on lambs fed diets with different NDF levels

\begin{tabular}{|c|c|c|c|c|c|c|c|}
\hline \multirow[b]{2}{*}{ Item } & \multicolumn{3}{|c|}{$\begin{array}{c}\text { Nível de FDN } \\
\text { NDF level }\end{array}$} & & \multirow[t]{2}{*}{$\mathrm{CV}(\%)$} & \multirow[t]{2}{*}{$\mathrm{R}^{2}$} & \multirow[t]{2}{*}{$\begin{array}{l}\text { Equação } \\
\text { Equation }\end{array}$} \\
\hline & 25 & 31 & 37 & 43 & & & \\
\hline $\mathrm{CC}$ & 54,90 & 56,58 & 54,44 & 54,96 & - & 3,49 & $\hat{\mathrm{Y}}=55,24$ \\
\hline $\begin{array}{l}C L \\
\mathrm{LP} \\
L W\end{array}$ & 9,30 & 9,28 & 9,10 & 9,68 & - & 6,20 & $\hat{\mathrm{Y}}=9,34$ \\
\hline $\begin{array}{l}\text { PPEITO } \\
C P\end{array}$ & 23,20 & 23,34 & 22,60 & 24,02 & - & 5,24 & $\hat{\mathrm{Y}}=23,29$ \\
\hline $\begin{array}{l}\text { CPERNA } \\
L L\end{array}$ & 36,10 & 35,30 & 34,10 & 35,60 & 0,37 & 2,73 & 1 \\
\hline
\end{tabular}

associado ao maior peso de abate dos animais alimentados com menores níveis de FDN. Kempster et al. (1987) descreveram que a deposição de gordura na carcaça ocorre de forma rápida pelo lombo e costilhar, o que pode estar associado à maior deposição de gordura nesta região nos animais alimentados com dietas mais energéticas. As demais variáveis analisadas não foram influenciadas significativamente $(\mathrm{P}>0,05)$ pelos níveis de FDN das rações.

Valores semelhantes aos obtidos neste trabalho para as proporções de perna, paleta, costilhar e pescoço foram encontrados por Frescura et al. (2005), que, trabalhando com cordeiros cruza Ile de France x Texel confinados e abatidos com $28,3 \mathrm{~kg}$ de PV, verificaram valores médios de 34,$02 ; 19,52 ; 37,34$ e $9,17 \%$, respectivamente. 
Tabela 6 - Valores médios para os pesos e as proporções de perna, paleta, costilhar e pescoço de cordeiros alimentados com dietas contendo diferentes níveis de FDN

Table 6 - Average values for the weight and proportions of hind leg, shoulder clod, rib, and neck on lambs fed diets with different NDF levels

\begin{tabular}{|c|c|c|c|c|c|c|c|}
\hline \multirow[t]{2}{*}{$\begin{array}{l}\text { Item } \\
\text { Item }\end{array}$} & \multicolumn{4}{|c|}{$\begin{array}{c}\text { Nível de FDN } \\
\text { NDF level }\end{array}$} & \multirow[t]{2}{*}{$\mathrm{R}^{2}$} & \multirow[t]{2}{*}{$\mathrm{CV}(\%)$} & \multirow[t]{2}{*}{$\begin{array}{l}\text { Equação } \\
\text { Equation }\end{array}$} \\
\hline & 25 & 31 & 37 & 43 & & & \\
\hline Perna (kg) (Hind leg, kg) & 2,35 & 2,26 & 2,10 & 2,17 & - & 7,41 & $\hat{\mathrm{Y}}=2,21$ \\
\hline Perna $(\%)$ (Hind leg, \%) & 34,08 & 33,50 & 33,64 & 34,76 & - & 2,96 & $\hat{\mathrm{Y}}=33,99$ \\
\hline Paleta (kg) (Shoulder clod, $\mathrm{kg}$ ) & 1,38 & 1,36 & 1,26 & 1,27 & - & 7,96 & $\hat{\mathrm{Y}}=1,31$ \\
\hline Paleta (\%) (Shoulder clod, \%) & 20,06 & 20,14 & 20,36 & 20,42 & - & 7,36 & $\hat{\mathrm{Y}}=20,25$ \\
\hline Costilhar $(\mathrm{kg})(R i b, k g)$ & 2,57 & 2,48 & 2,33 & 2,29 & 0,29 & 7,16 & 1 \\
\hline Costilhar $(\%)(R i b, \%)$ & 37,27 & 36,81 & 37,44 & 36,76 & - & 4,61 & $\hat{Y}=37,05$ \\
\hline Pescoço $(\mathrm{kg})($ Neck, $k g)$ & 0,59 & 0,64 & 0,59 & 0,62 & - & 11,73 & $\hat{\mathrm{Y}}=0,61$ \\
\hline $\operatorname{Pescoço~}(\%)(N e c k, \%)$ & 8,53 & 9,54 & 9,49 & 9,85 & - & 9,85 & $\hat{\mathrm{Y}}=9,39$ \\
\hline
\end{tabular}

1 - Costilhar $=2,88-0,014 \mathrm{FDN}^{*}$

* significativo a $5 \%$ de probabilidade pelo teste $\mathrm{F}$.

FDN = nível de fibra em detergente neutro da dieta.

* Significant at $5 \%$ probability by $F$ test.

$N D F=$ Neutral detergent fiber level in the diets.

Os valores médios referentes ao peso eà proporção de osso, músculo e gordura da perna dos cordeiros, de acordo com o nível de FDN das dietas, são apresentados na Tabela 7. Os diferentes níveis de fibra na dieta não influenciaram significativamente $(\mathrm{P}>0,05)$ a formação dos tecidos da perna dos cordeiros. Os resultados obtidos neste estudo foram próximos aos encontrados por Carvalho et al. (1998), que, trabalhando com cordeiros resultantes do acasalamento de carneiro da raça Texel com ovelhas cruzas (Ideal x Texel) terminados em confinamento e abatido s com peso vivo médio de 27,09 $\mathrm{kg}$ aos 100 dias de idade, verificaram valores médios para osso, músculo e gordura, respectivamente, de 18,$24 ; 71,72$ e $10,03 \%$ nos machos inteiros, 17,36; 71,06 e 11,58\% nos machos castrados e 17,$69 ; 71,50$ e $10,50 \%$ nas fêmeas.
Garcia et al. (2003), testando diferentes níveis de energia na dieta de cordeiros Suffolk alimentados em creep feeding, verificaram efeito quadrático dos níveis de energia na ração apenas para a gordura intermuscular, com valor mínimo estimado para o nível 2,74 Mcal EM/kg MS e quantidade superior de gordura intermuscular para o nível de 3,0 Mcal EM/kg MS. Quanto à quantidade de gordura total, os autores não observaram efeito significativo, resultado semelhante ao deste trabalho.

Em outro estudo, Preziuso et al. (1999) avaliaram dietas com diferentes fontes de energia na terminação de cordeiros da raça Appenine. Na dieta 1 incluíram 9\% de cevada floculada e, na dieta 2 , adicionaram $5 \%$ de óleo de milho; ambas foram fornecidas com feno de alfafa, à vontade. A dieta 3 apresentava a mesma composição percentual da 2 ,

Tabela 7 - Valores médios para os pesos e as proporções de osso, músculo e gordura da perna dos cordeiros alimentados com dietas com diferentes níveis de FDN

Table 7 - Average values for the weight and proportions of hind leg bone, muscle and fat on lambs fed diets with different NDF levels

\begin{tabular}{|c|c|c|c|c|c|c|c|}
\hline \multirow[b]{2}{*}{ Item } & \multicolumn{4}{|c|}{$\begin{array}{c}\text { Nível de FDN } \\
\text { NDF level }\end{array}$} & \multirow[t]{2}{*}{$\mathrm{CV}(\%)$} & \multirow[t]{2}{*}{$\mathrm{R}^{2}$} & \multirow[t]{2}{*}{$\begin{array}{l}\text { Equação } \\
\text { Equation }\end{array}$} \\
\hline & 25 & 31 & 37 & 43 & & & \\
\hline $\begin{array}{l}\text { Osso }(\mathrm{kg}) \\
\text { Bone }\end{array}$ & 0,467 & 0,448 & 0,442 & 0,457 & - & 6,46 & $\hat{\mathrm{Y}}=0,453$ \\
\hline Osso (\%) & 20,42 & 19,74 & 21,56 & 21,44 & - & 9,95 & $\hat{\mathrm{Y}}=20,81$ \\
\hline $\begin{array}{l}\text { Bone } \\
\text { Músculo (kg) } \\
\text { Muscle }\end{array}$ & 1,633 & 1,612 & 1,478 & 1,551 & - & 9,31 & $\hat{\mathrm{Y}}=1,565$ \\
\hline Músculo (\%) & 71,38 & 71,06 & 71,36 & 71,92 & - & 3,27 & $\hat{\mathrm{Y}}=71,43$ \\
\hline $\begin{array}{l}\text { Muscle } \\
\text { Gordura (kg) }\end{array}$ & 0,188 & 0,208 & 0,148 & 0,144 & - & 32,34 & $\hat{\mathrm{Y}}=0,171$ \\
\hline $\begin{array}{l}\text { Fat } \\
\text { Gordura (\%) } \\
\text { Fat }\end{array}$ & 8,19 & 9,20 & 7,08 & 6,63 & - & 29,50 & $\hat{\mathrm{Y}}=7,75$ \\
\hline
\end{tabular}


porém sem o feno. Depois de efetuada a dissecação da perna, os autores verificaram para as dietas 1,2 e 3, respectivamente, valores de 8,$55 ; 8,26$ e $11,44 \%$ de gordura. Os autores demonstraram que a redução dos níveis de fibra na dieta proporcionou efeito significativo sobre a deposição de gordura subcutânea na perna de cordeiros.

\section{Conclusões}

O aumento do teor de fibra na ração de cordeiros cruza Ile de France $\mathrm{x}$ Texel terminados em confinamento promoveu diminuição nos pesos e nos rendimentos de carcaça quente e fria.

A composição regional da carcaça e a composição tecidual da perna dos cordeiros não foram influenciadas pelo aumento do teor de FDN das dietas.

\section{Literatura Citada}

ALMEIDA JR., G.A.; COSTA, C.; MONTEIRO, A.L.G. et al. Desempenho, características de carcaça e resultado econômico de cordeiros criados em creep feeding com silagem de grãos úmidos de milho. Revista Brasileira de Zootecnia, v.33, n.4, p.1048-1059, 2004.

CARDOSO, A.R.; PIRES, C.C.; CARVALHO, S. et al. Efeito de diferentes níveis de FDN sobre a composição regional da carcaça de cordeiros terminados em confinamento. In: REUNIÃO ANUAL DA SOCIEDADE BRASILEIRA DE ZOOTECNIA, 41., 2004, Campo Grande. Anais... Campo Grande: Sociedade Brasileira de Zootecnia. 2004. (CD-ROM)

CARVAlHO, S.; PIRES, C.C.; MÜLLER, M. et. al. Composição tecidual da carcaça, quarto, paleta, costela, espinhaço e pescoço de cordeiros inteiros, castrados e fêmeas. In: REUNIÃO ANUAL DA SOCIEDADE BRASILEIRA DE ZOOTECNIA, 35., 1998, Botucatu. Anais... Botucatu: Sociedade Brasileira de Zootecnia, 1998. p.107-109.

COLOMER-ROCHER, F. Producción de canales ovinas frente al mercado común europeo. Zaragoza: Institución Fernando el Católico, 1986. 111p. (Publicación, 1052)

CUNHA, E.A.; SANTOS, L.F.; BUENO, M.S. et al. Utilização de carneiros de raças de corte para obtenção de cordeiros precoces para abate em plantéis produtores de lã. Revista Brasileira de Zootecnia, v.29, n.1, p.243-252, 2000.

DUMONT, B.L.; LEGRAS, P.; VERGES, J.C. Not sur une nouvelle méthode d'estimation de la conformation des animaux. Annales Zootechnie, v.19, n.2, p.235-237, 1970.

FRESCURA, R.B.M.; PIRES, C.C.; SILVA, J.H.S. et al. Avaliação das proporções dos cortes da carcaça, características da carne e avaliação dos componentes do peso vivo de cordeiros. Revista Brasileira de Zootecnia, v.34, n.1, p.167-174, 2005

GALVÃO, J.G.; FONTES, C.A.A.; PIRES, C.C. et al. Caracterização e composição física da carcaça de bovinos não castrados, abatidos em três estágios de maturidade de três grupos raciais. Revista Brasileira de Zootecnia, v.20, p.502-512, 1991.

GARCIA, C.A. Avaliação do resíduo de panificação "biscoito" na alimentação de ovinos e nas características quantitativas e qualitativas da carcaça. Jaboticabal: Universidade Estadual Paulista, 1998. 79p. Dissertação (Mestrado em Zootecnia) - Universidade Estadual Paulista, 1998.

GARCIA, C.A.; MONTEIRO, A.L.G.; COSTA, C. et al. Medidas objetivas e composição tecidual da carcaça de cordeiros alimentados com diferentes níveis de energia em creep feeding. Revista Brasileira de Zootecnia, v.32, n.6, p.1380-1390, 2003.

GARCIA, I.F.F.; PEREZ, J.R.O.; OLIVEIRA, M.V. Características de carcaça de cordeiros Texel x Bergamácia, Texel x Santa Inês e Santa Inês Puros, terminados em confinamento, com casca de café como parte da dieta. Revista Brasileira de Zootecnia v.30, n.3, p.253-260, 2000 .

GIOTTO, E. Manual Siter 3.1. Santa Maria: Universidade Federal de Santa Maria, 2001. 187p.

HUIDOBRO, F.R. Estudios sobre crecimiento y desarrollo en corderos de raza manchega. Madrid: Universidad Complutense, 1992. 191p. Tese (Doutorado em Veterinaria) Universidad Complutense, 1992.

HUIDOBRO, F.R.; CAÑEQUE, V. Producción de carne de raza Manchega. II. Conformación y estado de engarzamiento de la canal y proporción de piezas en distintos tipos comerciales. Investigación Agraria Producción y Sanidad Animal, v.8, n.3, p.233-243, 1993.

KEMPSTER, A.J.; CROSTON, D.; GUY, D.R. et al. Growth and carcass characteristics of crossbred lambs by tem sire breeds, compared at the same estimated carcass subcutaneus fat proportion. Animal Production, v.44, n.1, p.83-98, 1987.

LATHAN, S.D.; MOODY, U.; KEMP, J.D. et al. Reliability of predicting lamb carcass composition. Journal of Animal Science, v.23, p.861-865, 1964.

LAWRENCE, T.L.J.; FOWLER, V.R. Growth of farm animals London: Cambridge University, 1997. 330p.

MACEDO, F.A.F.; SIQUEIRA, E.R.; MARTINS, E.N. et al. Qualidade de carcaças de cordeiros Corriedale, Bergamácia $\mathrm{x}$ Corriedale e Hampshire Down x Corriedale, terminados em pastagem e confinamento. Revista Brasileira de Zootecnia, v. 29, n.5, p. $1520-1527,2000$.

OLIVEIRA, M.V.M., PEREZ, J.R.O.; ALVES, E.L. et al. Rendimento de carcaça, mensurações e peso de cortes comerciais de cordeiros Santa Inês e Bergamácia alimentados com dejetos de suínos em confinamento. Revista Brasileira de Zootecnia, v.31, n.3, p.1451-1458, 2002 (supl. 1)

MATOS, M.S.; MATOS, P.F. Laboratório clínico médicoveterinário. 2.ed. Rio de Janeiro: Atheneu, 1988. 238p.

MORENO, J.A. Clima do Rio Grande do Sul. Porto Alegre: Secretaria da Agricultura. 1961. 41p.

MOTTA, O.S.; PIRES, C.C.; SILVA, J.H.S. et. al. Avaliação da carcaça e cordeiros da raça Texel sob diferentes métodos de alimentação e pesos de abate. Ciência Rural, v.31, n.6, p.1051-1056, 2001.

MÜLLER, L. Normas para avaliação de carcaça e concurso de carcaças de novilhos. Santa Maria: Universidade Federal de Santa Maria, Departamento de Zootecnia, 1980. 31p.

NERES, M.A.; MONTEIRO, A.L.G.; GARCIA, C.A. et al. Forma física da ração e pesos de abate nas características de carcaça de cordeiros em creep feeding. Revista Brasileira de Zootecnia, v.30, n.3, p.948-954, 2001 (supl. 1)

OSÓRIO, J.C.S. Estudio de la calidad de canales comercializadas en el tipo ternasco según la procedencia: bases para la mejora de dicha calidad en Brasil. Zaragoza: Universidad de Zaragoza, 1992. 335p. Tese (Doutorado em Veterinária) - Universidad de Zaragoza, 1992.

OSÓRIO, J.C.S.; ASTIZ, C.S.; OSÓRIO, M.T. et al. Produção de carne ovina, alternativa para o Rio Grande do Sul. Pelotas: Universidade Federal de Pelotas, 1998a. 136p.

OSÓRIO, J.C.S.; OSÓRIO, M.T.M.; JARDIM, P.O.C. et al. Métodos para avaliação da produção de carne ovina, in vivo, na carcaça e na carne. Pelotas: Universidade Federal de Pelotas, 1998b. 107p

OWENS, F.N.; GILL, D.R. Review of some aspects of growth and development of feedlot cattle. Journal of Animal Science, v.73, n.10, p.3152-3172, 1995.

PATTERSON, D.C.; STEEN, R.W.; KILPATRICK, D.J. Growth and development in beef cattle. 1. Direct and residual effect of 
plane of nutrition during early life on components of gain and food efficiency. Journal of Agricultural Science, v.124, n.1, p.91-100, 1995.

PREZIUSO, G.; RUSSO, C.; CASAROSA, L et al. Effect of diet energy source on weight gain and carcass characteristics of lambs. Small Ruminant Research, v.33, n.1, p.9-15, 1999.

STATISTICAL ANALYSIS SYSTEM - SAS. User's guide. Versão 6, 4.ed. Cary: 1997. 846p.

SAINZ, D.R. Qualidades das carcaças a da carne ovina e caprina. In: REUNIÃO ANUAL BRASILEIRA DE ZOOTECNIA, 33., 1996, Fortaleza. Anais... Fortaleza: Sociedade Brasileira de Zootecnia, 1996. p.7.

SILVA, D.J. Análise de alimentos: métodos químicos e biológicos. Viçosa, MG: Universidade Federal de Viçosa, 1990. 166p.

SILVA, L.F.; PIRES, C.C. Avaliações quantitativas e predição das proporções de osso, músculo e gordura da carcaça em ovinos. Revista Brasileira de Zootecnia, v.29, n.4, p.1253-1260, 2000.

SIQUEIRA, E.R.; FERNANDES, S. Pesos, rendimentos e perdas da carcaça de cordeiros Corriedale e mestiços Ile de France $x$ Corriedale, terminados em confinamento. Ciência Rural, v.29, n.1, p.143-148, 1999.
SIQUEIRA, E.R.; FERNANDES, S. Efeito do genótipo sobre as medidas objetivas e subjetivas da carcaça de cordeiros terminados em confinamento. Revista Brasileira de Zootecnia, v.29, n.1, p.306-311, 2000.

SNIFFEN, C.J.; O'CONNOR, J.D.; Van SOEST, P.J. et al. A net carbohydrate and protein system for evaluating cattle diets. 2. Carbohydrate and protein availability. Journal of Animal Science, v.70, n.11, p.3562-3577, 1992.

SOUSA, O.R.C. Rendimento de carcaça, composição regional e física da paleta e quarto em cordeiros Romney Marsh abatidos aos 90 e 180 dias de idade. Pelotas: Universidade Federal de Pelotas, 1993. 102p. Dissertação (Mestrado em Zootecnia) - Universidade Federal de Pelotas, 1993.

WEISS, W.P. Predicting energy values of feeds.Journal of Dairy Science, v.76, n.6, p.1802-1811, 1993.

Recebido: 21/03/05 
